\title{
Prolactin receptor expression in the epithelia and stroma of the rat mammary gland
}

\author{
I G Camarillo, G Thordarson, J G Moffat, K M Van Horn, \\ N Binart ${ }^{1}$, P A Kelly ${ }^{1}$ and $\mathbf{F}$ Talamantes \\ Department of Biology, University of California, Santa Cruz, California 95064, USA \\ ${ }^{1}$ INSERM Unit 344-Endocrinologie Moleculaire, Faculte de Medicine Necker, 156 rue de Vaugirard, 75730 Paris, France \\ (Requests for offprints should be addressed to F Talamantes, Department of Biology, Sinsheimer Laboratories, University of California, Santa Cruz, \\ California 95064, USA; Email: prolactin@aol.com)
}

\begin{abstract}
The importance of prolactin (PRL) in regulating growth and differentiation of the mammary gland is well known. However, it is not well established whether PRL acts solely on the mammary epithelia or if it can also directly affect the mammary stroma. To determine where PRL could exert its effects within the mammary gland, we investigated the levels of expression and the localization of the PRL receptor (PRLR) in the epithelia and stroma of the rat mammary gland at different physiological stages. For these studies, we isolated parenchymal-free 'cleared' fat pads and intact mammary glands from virgin, 18-daypregnant and 6-day-lactating rats. In addition, intact mammary tissues were enzymatically digested to obtain epithelial cells, free of stroma. The mammary tissues, intact gland, stroma and isolated epithelia, were then used for immunocytochemistry, protein extraction and isolation of total RNA. PRLR protein was detected in tissues using specific polyclonal antisera (PRLR-1) by immunocytochemistry and Western blot analysis. Messenger RNA for PRLR was measured by ribonuclease protection assay. Immunocytochemistry and Western blots with the PRLR-1 antisera detected PRLR in wild-type rat and mouse tissues, whereas the receptor protein was absent in tissues from PRLR gene-deficient mice. PRLR was
\end{abstract}

found to be present both in the epithelia and stroma of mammary glands from virgin, pregnant and lactating rats, as determined by immunocytochemistry and Western blotting. Western blots revealed the predominance of three bands migrating at 88,90 and $92 \mathrm{kDa}$ in each of the rat mammary samples. These represent the long form of the PRLR. During pregnancy and lactation, PRLR protein increased in the epithelial compartment of the mammary gland but did not change within the stromal compartment at any physiological stage examined. We also found PRLR mRNA in both the epithelia and stroma of the mammary gland. Again, the stroma contained lower levels of PRLR mRNA compared with the epithelia at all physiological stages examined. Also, the PRLR mRNA levels within the stroma did not change significantly during pregnancy or lactation, whereas PRLR mRNA within the epithelia increased twofold during pregnancy and fourfold during lactation when compared with virgin rats. We conclude from this study that PRLR is expressed both in the stromal and epithelial compartment of the mammary gland. This finding suggests PRL may have a direct affect on the mammary stroma and by that route affect mammary gland development.

Journal of Endocrinology (2001) 171, 85-95

\section{Introduction}

Prolactin (PRL) is a polypeptide hormone produced mainly in the pituitary but is also synthesized by peripheral tissues. A recent review (Bole-Feysot et al. 1998) cites more than 300 separate functions in vertebrates which are attributable to PRL. Of these actions, PRL is probably best known for its role in mammary gland development and lactation. PRL exerts its actions by binding to a single-pass transmembrane receptor (PRLR) belonging to the class-1 cytokine receptor superfamily (Bole-Feysot et al. 1998). Although PRLRs have been identified in a variety of species (Bole-Feysot et al. 1998), the rat (r)
PRLR is probably the best characterized. The rPRLR exists in three isoforms (short, intermediate and long) that result from alternative splicing of a primary transcript. These isoforms differ in length and composition of their cytoplasmic domains but their extracellular hormone binding domains are identical (Goffin \& Kelly 1997). The intermediate form of the rPRLR has only been found in the $\mathrm{Nb} 2$ lymphoma cell line, whereas the long and short isoforms are expressed in normal tissues (Goffin \& Kelly 1997). Previous studies revealed the ubiquitous expression of both the long and short isoforms of the PRLR in the rat (Goffin et al. 1999). However, expression ratio of the long and short isoforms is dependent on tissue type and 
physiological state of the animal, with PRLR long form being predominant in most tissues (Nagano \& Kelly 1994).

It is well established that many hormones, including growth hormone $(\mathrm{GH})$, estrogen, progesterone and PRL, are necessary for the growth and differentiation of the mammary gland (Lyons et al. 1958, Forsyth 1989, Rillema 1994). The early studies of Lyons et al. (1958) and Nandi (1958) established the importance of the sequential hormone effects in mammary gland development. Briefly, estrogen and $\mathrm{GH}$ are essential for mammary duct development, progesterone caused ductal side branching and alveolar development required the presence of PRL. The main emphasis in the effort of elucidating the role hormones play in regulating mammary development has been on how hormones affect the epithelial cells. However, increasing evidence now supports the notion that besides its role as a support matrix, the mammary fat pad is also a source of lipids, growth factors and extracellular matrix factors, and that the stromal-epithelial interaction is critically important for epithelial growth and morphogenesis. Therefore, hormones that regulate mammary gland growth and differentiation could be exerting their effects on the epithelia and/or the stroma (Hovey et al. 1999). For example, receptors for GH (Lincoln et al. 1995, Mertani et al. 1998, Ilkbahar et al. 1999), estrogen (Fendrick et al. 1998) and progestins (Shyamala 1999) have been localized in both the epithelial and stromal components of the mammary gland, suggesting that these hormones may be acting directly and/or indirectly in the mammary gland. It has not been determined whether PRL could be exerting some of its complex effects in the mammary gland via the regulation of stromal factors. However, recent studies (Ling et al. 2000, Freemark et al. 2001) that reveal the expression of PRL receptor in mouse adipose tissue may support this hypothesis.

As a first step in addressing this question, we set out to determine if the PRLR could be detected both in epithelial and stromal components of the rat mammary gland. For these studies, mammary tissues from three physiological stages were used, and the detection of the PRLR protein was carried out with immunocytochemistry and Western blot analysis using a specific PRLR antiserum. In addition, the mRNA levels for the PRLR were measured in mammary epithelial and stromal samples obtained from identical physiological stages using a ribonuclease protection assay.

\section{Materials and Methods}

\section{Animals and experimental design}

Timed pregnant (day plug found $=$ day 0 of pregnancy) and age-matched virgin Sprague-Dawley rats were purchased from Simonsen Laboratories (Gilroy, CA, USA). All the rats were kept in a temperature-controlled $\left(18-25^{\circ} \mathrm{C}\right)$ vivarium, with lights on between $0600 \mathrm{~h}$ and $2000 \mathrm{~h}$; food and water were available ad libitum. All protocols for the care and use of animals in this study were approved by the Chancellor's Animal Research Committee of the University of California, Santa Cruz.

Young virgin rats at three weeks of age were anesthetized by a single intra-peritoneal injection of a mixture of ketamine (Aveco Co., Inc., Fort Dodge, IA, USA) and xylazine (Mobay Co., Shawnee, KS, USA) at a dose of $30 \mathrm{mg}$ ketamine: $6 \mathrm{mg}$ xylazine $/ \mathrm{kg}$ body weight. Using the methods of DeOme et al. (1959), the fourth pair of mammary glands was cleared of the epithelial rudiments by cauterization. This procedure has been successfully performed in our laboratory previously (Ilkbahar et al. 1999). All other pairs of mammary glands were left intact. At 8 weeks of age, some of the rats were mated, and the remaining animals were maintained as virgins until death. Of the mated animals, some were killed on day 18 of gestation while the remaining mated rats were kept until after parturition. Parous rats were allowed to nurse pups until they were killed on the sixth day of lactation. Intact mammary tissues (the second and third pairs) and epithelia-free fat pads (the fourth pair) were collected. Cleared fat pads and intact glands were used for histological preparations and the remaining tissue frozen in liquid nitrogen and stored at $-80{ }^{\circ} \mathrm{C}$ for later use in Western blots or ribonuclease protection assays (RPAs). Hematoxylin and eosin stained histological preparations of the cleared fat pads were inspected to ensure no epithelial ingrowths had occurred. Some of the intact glands were immediately prepared for enzymatic digestion to isolate stroma-free epithelial cells. Isolated epithelia were then immediately frozen at $-80{ }^{\circ} \mathrm{C}$ for later use in Western blots or RPAs (see Fig. 1).

\section{Anti-PRLR antiserum production}

A synthetic peptide corresponding to amino acids 29-46 (PRLR-1 peptide) of the rPRLR and mouse (m) PRLR (Kelly et al. 1993) was synthesized. This peptide was then used for the preparation of polyclonal antisera (PRLR-1). Both the synthesis of the peptide and the generation of the antisera were carried out by Bio-Synthesis, Inc. (Lewisville, TX, USA) according to their First Class procedure, using rabbits for the generation of the antiserum. The antisera used for detection of the growth hormone receptor, GHR-2, was generated in our laboratory and has been characterized previously (Camarillo et al. 1998). This antiserum recognizes both the mouse and rat growth hormone receptor.

\section{Immunocytochemistry}

Paraffin-embedded sections of $4 \%$ paraformaldehyde-fixed intact mammary glands and epithelia-free fat pads were immunostained with PRLR-1 using the Vectastain ABC 


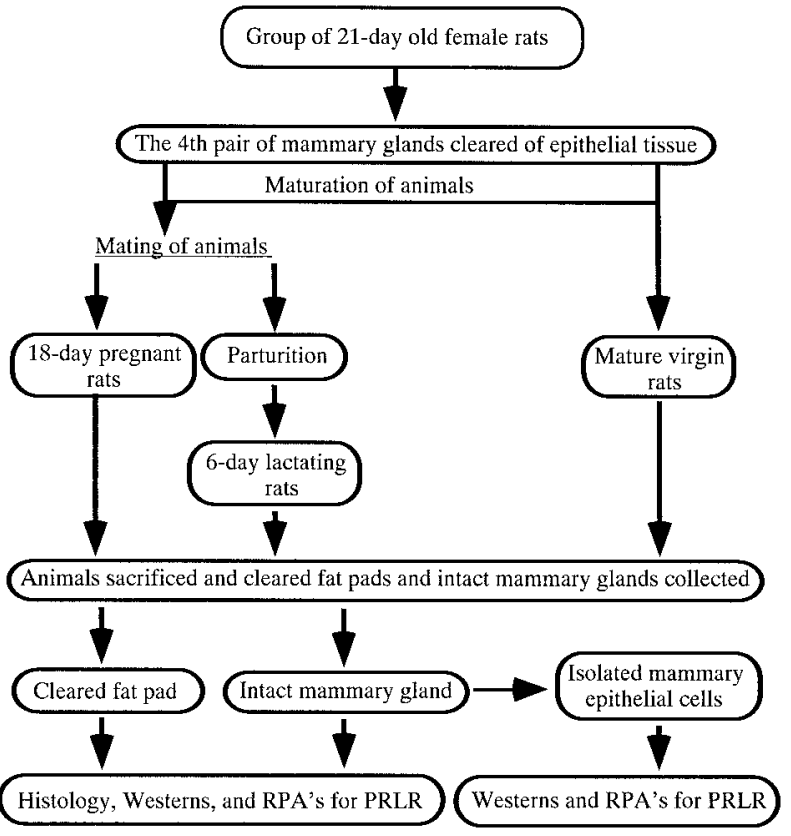

Figure 1 A schematic representation of the experimental procedure used for these studies. See Materials and Methods for a more detailed description.

kit (Vector Laboratories, Burlingame, CA, USA). Briefly, paraffin-embedded tissues were sectioned to $5 \mu \mathrm{m}$ and after rehydration, the sections were treated with $0 \cdot 2 \%$ glycine in PBS for $10 \mathrm{~min}$ to block aldehyde groups, followed by treatment with $0.3 \% \mathrm{H}_{2} \mathrm{O}_{2}$ in methanol for $30 \mathrm{~min}$ to block endogenous peroxidases. Nonspecific protein binding was blocked by incubating the sections first with $2 \%$ dried milk for $30 \mathrm{~min}$ and then with $5 \%$ goat serum in PBS for $3 \mathrm{~h}$. PRLR-1 antiserum was diluted 1:500 in PBS and then added onto the tissue sections for overnight incubation at $22{ }^{\circ} \mathrm{C}$. Biotinylated secondary antibody (goat anti-rabbit) was diluted to $0.5 \%(\mathrm{v} / \mathrm{v})$ in PBS containing $1 \cdot 0 \%$ normal goat serum and the tissue sections were incubated in the secondary antiserum for $30 \mathrm{~min}$ at $22^{\circ} \mathrm{C}$. After washing, these mammary sections were incubated for $30 \mathrm{~min}$ at $22^{\circ} \mathrm{C}$ in the $\mathrm{ABC}$ reagent diluted 25 times in PBS containing 1.0\% goat serum. Tissue sections were then stained with a substrate solution consisting of $0.1 \%$ diaminobenzidine and $0.02 \% \mathrm{H}_{2} \mathrm{O}_{2}$ (Vector Laboratories) in $0 \cdot 1 \mathrm{M}$ Tris $\mathrm{HCl}$ buffer, $\mathrm{pH} 7 \cdot 0$. The sections were washed between steps in PBS. After immunostaining, the tissue sections were counterstained in $0.25 \%$ methyl-green.

On each slide, a control section was incubated with PRLR-1 primary antiserum that was preadsorbed for $3 \mathrm{~h}$ at $4{ }^{\circ} \mathrm{C}$ with $20 \mu \mathrm{g} / \mathrm{ml}$ PRLR-1 peptide. Two other types of controls were also included. These were mammary sections incubated with normal rabbit serum $(1: 500)$ that replaced the primary antiserum, and sections prepared from intact mammary glands of PRLR gene-deficient mice (PRLR - / - mice) immunostained with the PRLR-1 antisera. Each of the controls was subjected to a protocol identical to that used on sections immunostained for PRLR, as described above.

\section{Isolation of mammary epithelial cells}

Intact mammary glands freshly dissected from 18-daypregnant and 6-day-lactating animals (3 glands for each preparation) were minced with a razor blade and then incubated at $37^{\circ} \mathrm{C}$ with gentle shaking for $1 \mathrm{~h}$ in Hank's balanced salt solution (HBSS) containing 0.004\% DNAse and $0 \cdot 1 \%$ collagenase. Three batches of isolated epithelial cells from each physiological state were prepared. After the dissociation was complete, the cell suspension was fractionated on a $38 \%$ continuous Percoll gradient. The epithelial cells were washed extensively in HBSS and any endothelial contaminants were removed by sedimentation. The purity of the resulting epithelial cell population was verified by microscopic inspection. The cells were frozen on dry ice and stored at $-80{ }^{\circ} \mathrm{C}$ until RNA or protein isolation.

\section{Tissue collections}

For the PRLR RPA and Western blot the epithelia-free fat pads from virgin, 18-day-pregnant, 6-day-lactating rats (4 pooled samples of 3-4 glands per animal group) and intact mammary glands from the same animal groups (4 pooled samples of 1-3 glands per animal group) were isolated. In addition, mammary glands and livers were collected from wild-type (PRLR $+/+$ mice) and PRLR gene-deficient mice (PRLR $-/-$ mice). These tissues were used as PRLR-positive and PRLR-negative controls, respectively, in Western blotting and immunocytochemistry. All tissues were washed in $0.9 \%$ saline, immediately frozen in liquid nitrogen and stored at $-80{ }^{\circ} \mathrm{C}$ until RNA or protein preparations.

\section{PRLR protein analysis}

Microsomal membranes were prepared from all liver and mammary tissue samples (intact mammary glands, isolated epithelial cells and epithelial free fat pads) as described previously (Camarillo et al. 1998). Briefly, tissues were homogenized on ice, in 4 times (w/v) homogenization buffer $(300 \mathrm{mM}$ sucrose, $50 \mathrm{mM}$ HEPES with protease inhibitors, $\mathrm{pH} 8 \cdot 0$ ) using a Polytron homogenizer. The homogenates were centrifuged at $20000 \mathrm{~g}$ for $30 \mathrm{~min}$. The resulting supernatant was centrifuged at $100000 \boldsymbol{g}$ for $1 \mathrm{~h}$ to pellet microsomal membrane fractions. The pellets were then washed in a buffer consisting of $50 \mathrm{mM}$ HEPES, $10 \mathrm{mM}$ EDTA, and protease inhibitors ( $\mathrm{pH} 7 \cdot 5$ ) and recentrifuged. Membrane proteins were solubilized by vigorous agitation of the pellets in solubilization buffer 


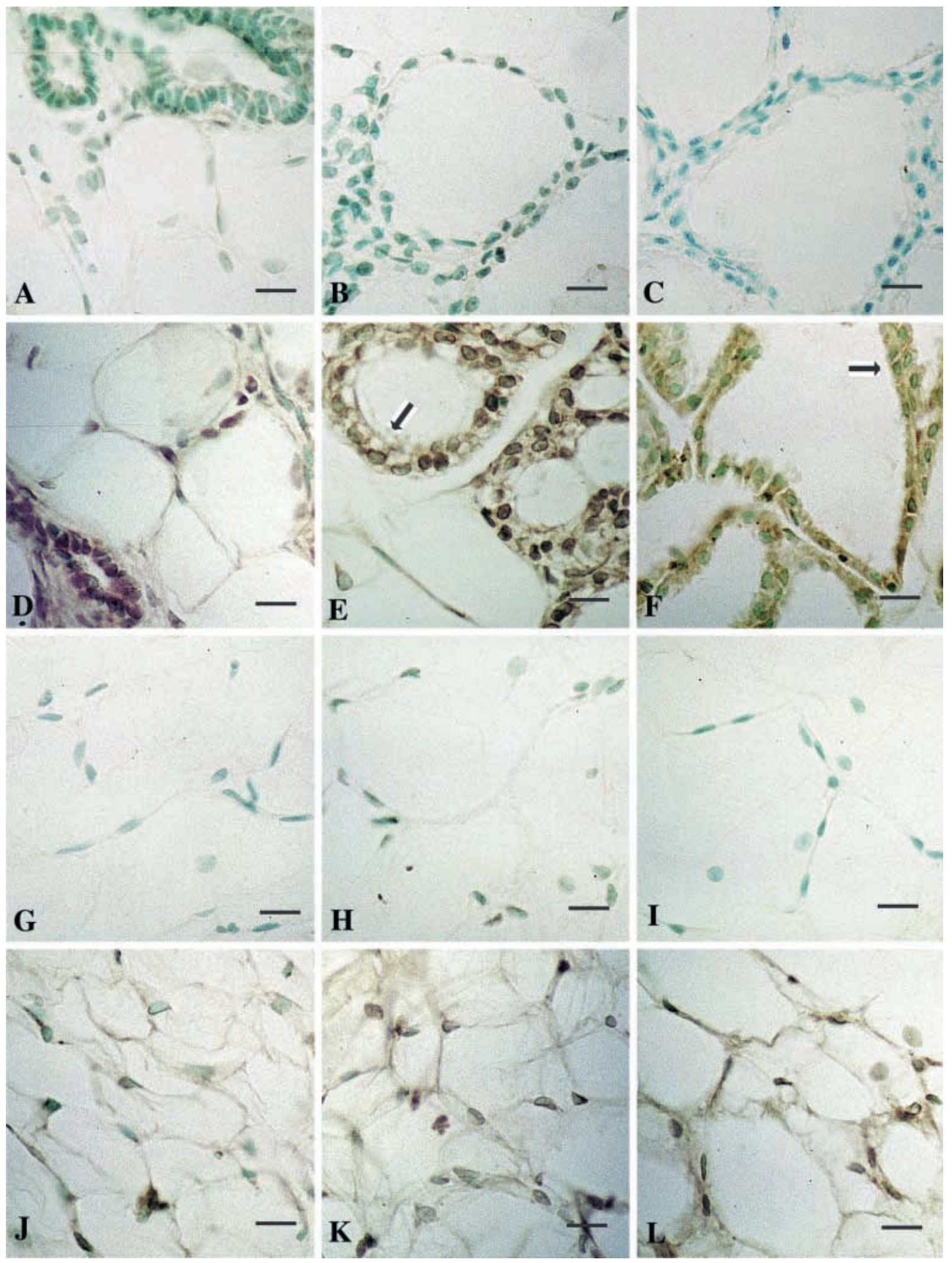


(10 mM EDTA, $150 \mathrm{mM} \mathrm{NaCl}$, and 2\% Triton X-100, $\mathrm{pH} 7 \cdot 5)$. An aliquot of each membrane preparation was assayed for total protein using the bicinchoninic acid (BCA) protein assay kit (Pierce, Rockford, IL, USA). Samples were then stored at $-80{ }^{\circ} \mathrm{C}$ for later use for Western blots.

\section{Western blots}

Solubilized membrane proteins from rat or mouse tissues $(60 \mu \mathrm{g}$ protein/lane for each mammary sample; $30 \mu \mathrm{g}$ protein/lane for each liver sample) were separated on a 10\% SDS-polyacrylamide gel under reducing conditions and transferred to polyvinylidenedifluoride (PVDF) membranes (Millipore, Bedford, MA, USA). Prestained standards (Bio-rad, Hercules, CA, USA) were used as molecular weight markers. The membranes were incubated with PRLR-1 antisera (diluted 1:1500) or GHR-2 antisera (diluted 1:8000) for $2 \mathrm{~h}$, followed by 30-min incubation with goat-anti-rabbit immunoglobulinG ( $\operatorname{IgG})$ horseradish peroxidase (HRP)-conjugate (Pierce, Rockford, IL, USA) diluted 1:50 000. The PRLR and GHR bands were detected using enhanced chemiluminescence reagents and hyperfilm (Amersham, Piscataway, NJ, USA) exposure. Control membranes, containing identical protein samples were subjected to the same protocol except that the PRLR-1 antisera were preincubated with PRLR-1 peptide $(10 \mu \mathrm{g} / \mathrm{ml})$.

\section{Ribonuclease protection assay}

Total RNA was extracted from intact glands, epitheliafree fat pads, and isolated epithelial cell samples obtained from nonpregnant, pregnant and lactating rats $(n=3$ for each group). RNA was isolated by the single-step guanidinium isothiocyanate-phenol-chloroform extraction method (Chomczynski \& Sacchi 1987). The integrity of the extracted RNA was confirmed by gel electrophoresis. RNA concentrations were determined by spectrophotometry.

An antisense RNA probe capable of differentiating between the long and short forms of the PRLR mRNA was generated as follows. PCR was used to amplify a fragment corresponding to nucleotides 640 to 892 of rPRLR long form cDNA. This region contains 201 nucleotides common to both the long and the short forms of the rPRLR mRNAs, and 51 nucleotides that are specific to the long form. Therefore, in the RPA, this probe protects a 201 nucleotide fragment of the mRNA for the PRLR short form and a 252 nucleotide fragment of the mRNA for the PRLR long form. The PCR product was ligated into pGEM-Teasy plasmid (Promega, Madison, WI, USA) and sequenced to confirm identity and orientation. In addition, a cyclophilin RNA probe, protecting a 103 nucleotide fragment of the rat cyclophilin mRNA was used as an internal control. The template to make the cyclophilin RNA probe was purchased from Ambion (Austin, TX, USA). Each probe was transcribed from its linearized plasmid template using T7 RNA polymerase and $\alpha\left[{ }^{32} \mathrm{P}\right] \mathrm{UTP}$ (MaxiScript kit, Ambion) according to the manufacturer's instructions. Gel-purified probes were used in RPAs (Hybspeed kit, Ambion) according to the manufacturer's instructions. For the assay, $15 \mu \mathrm{g}$ total RNA per reaction were used from intact and isolated epithelial cell samples and $30 \mu \mathrm{g}$ total RNA per reaction were used for stromal samples. In addition, a set of control reactions was performed in which the mRNA probes for PRLR and cyclophilin were incubated with yeast RNA in either the absence or presence of RNase. Each specific full-length probe remained intact in the absence of RNase and was completely digested when RNase was present. Signal intensities of bands corresponding to PRLR and cyclophilin mRNAs were quantitated by phospor-imaging. The RPA values for PRLR mRNA was normalized to the amount of the rat cyclophilin mRNA. The resulting data were analyzed by ANOVA followed by Fisher's protected least difference test. Difference between groups was considered significant when a $P$ value of $<0 \cdot 05$ was obtained.

\section{Results}

\section{Immunolocalization of PRLR in the rat mammary gland}

Specific staining for PRLR was observed in both the mammary stroma and epithelia of intact glands from all developmental stages analyzed (Fig. 2D-F). Epithelial PRLR was associated mainly with the cytosol and nucleus in mammary cells of virgin rats. In late pregnant rats, epithelial PRLR localization was more perinuclear and cell membrane associated. In contrast, PRLR immunostaining was strong within the cytosol of the epithelia from lactating rats (Fig. 2F). Also of interest is the staining of both apical and basal epithelial cell membranes during pregnancy (Fig. 2E).

\footnotetext{
Figure 2 (opposite) Photomicrographs showing immunocytochemical localization of PRLR within the mammary gland during three stages of development. Control mammary glands, where the primary antiserum was pre-incubated with PRLR- 1 control peptide, are shown for intact glands and fat pads of virgin rats (intact gland, A; fat pad, G), 18-day-pregnant rats (intact gland, B; fat pad, H) and 6-day-lactating rats (intact gland, C; fat pad, I). Immunolocalization of PRLR is apparent in intact mammary glands and epithelia-free fat pads of virgin rats (intact gland, D; fat pad, J), 18-day-pregnant rats (intact gland, E; fat pad, K) and 6-day-lactating rats (intact gland, F; fat pad, L). Scale bars represent $10 \mu \mathrm{m}$. The arrow in section E indicates the perinuclear and cell membrane localization of PRLR in adjacent epithelial cells of 18-day-pregnant rats. The arrow in section $\mathrm{F}$ indicates the cytosolic localization of PRLR in adjacent epithelial cells of 6-day-lactating rats.
} 
Specific staining for PRLR was also observed in epithelia-free fat pads from all three developmental states (Fig. 2J-L). Regardless of physiological stage, PRLR staining patterns and intensity were similar in fat pads. This PRLR localization in fat pads was nuclear, cytoplasmic and membrane associated. The PRLR immunostaining pattern, intensity and localization detected in epithelia-free fat pads were also seen in stroma of intact glands. Overall, staining in the periductal stroma was not as consistent or intense as staining in adipocytes of fat pads or intact glands. Preincubation of PRLR-1 antisera with PRLR-1 peptide completely blocked specific PRLR immunostaining in intact mammary glands and epitheliafree fat pads from virgin rats (intact gland, fat pads; Fig. 2A,G), 18-day-pregnant rats (Fig. 2B,H) and 6-daylactating animals (Fig. 2C,I). Replacement of primary antisera with normal rabbit serum also completely blocked specific PRLR immunostaining in virgin, late pregnant and lactating glands, as well as in epithelia-free fat pads (data not shown). Furthermore, when mammary glands of PRLR gene-deficient mice (PRLR - / - mice) were incubated with PRLR-1 antisera, no specific staining for PRLR was detectable in the epithelial or stromal cells (data not shown).

\section{PRLR protein distribution}

To confirm our histological data, solubilized membrane proteins of intact glands, isolated epithelia and cleared fat pads from three physiological stages were analyzed for PRLR by Western blot with the PRLR-1 antisera. Antisera specificity is shown in Fig. 3A where membrane solubilized liver (LIVER) and mammary gland (MMG) proteins from wild-type mice (PRLR $+/+$ mice) or PRLR gene-deficient mice (PRLR - / - mice) were probed with PRLR-1. The immunoblot revealed a predominant protein band of 92 kilodaltons $(\mathrm{kDa})$ in mammary gland and liver samples from wild-type mice (Fig. 3A, upper panel, +/+MMG and +/+LIVER). These results are consistent with previously published studies that detected mouse PRLR long form $\left(\mathrm{mPRLR}_{\mathrm{L}}\right)$ (Ling et al. 2000). The $92 \mathrm{kDa}$ protein was not detected in mammary gland and liver samples from PRLR genedeficient mice (Fig. 3A, upper panel, $-/-M M G$ and $-/$-LIVER). As an additional control, the membrane shown in the upper panel of Fig. 3A was stripped and re-probed with GHR-2, an antibody specific for mouse and rat GHR (Camarillo et al. 1998). In this blot, a predominant band was seen at approximately $100 \mathrm{kDa}$, which corresponds to the molecular weight of the mouse growth hormone receptor (mGHR) (Smith et al. 1988). Figure $3 \mathrm{~B}$ shows an immunoblot in which proteins from intact glands, isolated epithelia and cleared fat pads of virgin, pregnant and lactating rats were probed with PRLR-1 antisera. The rat (r) PRLR $\mathrm{L}_{\mathrm{L}}$ was predominant in all mammary tissues, as shown by the detection of three
A

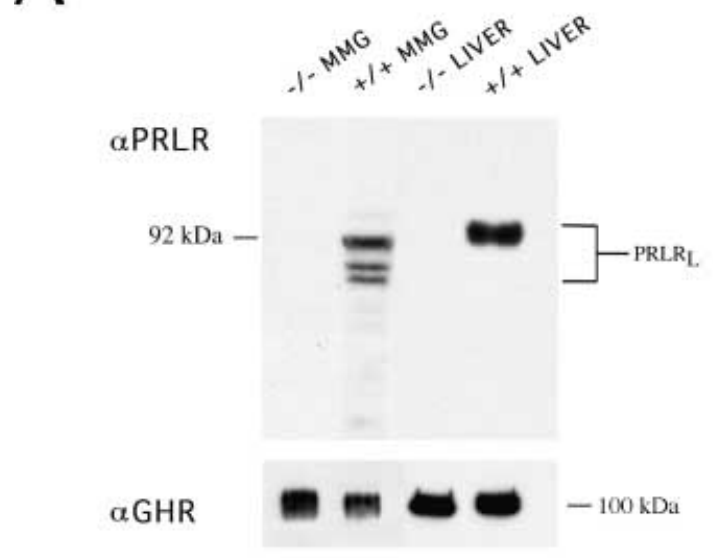

B

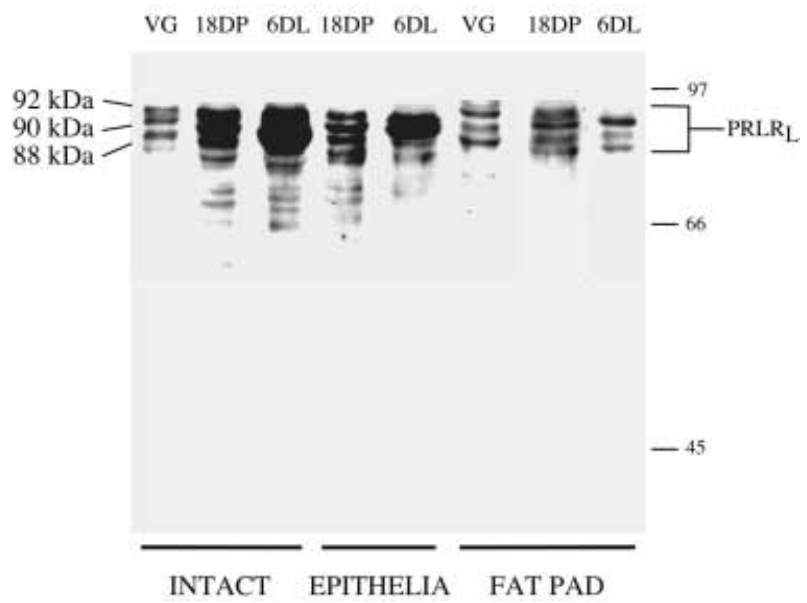

Figure 3 Western blot analysis of PRLR protein distribution within the mammary gland during three stages of development. (A) Upper panel: detection of PRLR protein in mammary gland tissue $(+/+$ MMG) and liver (+/+LIVER) of wild-type female mice by immunoblot analysis. Samples from mammary gland ( $-/-$ MMG) and liver (- / - LIVER) of PRLR gene-deficient mice were used as a negative control. Solubilized membrane proteins from mammary gland ( $60 \mu \mathrm{g} /$ lane) and liver ( $30 \mu \mathrm{g} / \mathrm{lane}$ ) tissues were separated by SDS-PAGE ( $10 \%$ gel) under reducing conditions. The resulting membrane was probed with PRLR-1 antisera. The position of the $92 \mathrm{kDa}$ band is indicated and represents the expected size of the long PRLR isoform $\left(\mathrm{PRLR}_{\mathrm{L}}\right)$ in the mouse. Lower panel: the membrane shown in the upper panel was stripped and re-probed with GHR-2, an antibody specific for GHR. The position of the $100 \mathrm{kDa}$ band is indicated and represents the expected size of the mouse GHR. (B) Solubilized membrane proteins ( $60 \mu \mathrm{g} / \mathrm{lane})$ of intact glands, isolated epithelia, and cleared fat pads from virgin rats (VG), 18-daypregnant rats (18DP) and 6-day-lactating rats $(6 \mathrm{DL})$ rats were separated by SDS-PAGE $(10 \%$ gel) under reducing conditions. The resulting membrane was probed with PRLR-1 antisera. Molecular weight standards are indicated on the right side of the figure, and the molecular weights of the rat long form prolactin receptor $\left(P R L R_{L}\right)$ are shown on the left. Each of the blots in this figure are representative of three separate experiments using different sample preparations. 
major bands migrating at 88,90 and $92 \mathrm{kDa}$ in all tissue samples. These bands are also comparable in size to the expected molecular weight of $\mathrm{rPRLR}_{\mathrm{L}}$ (Boutin et al. 1988, Guillaumot \& Cohen 1994). Bands corresponding to the short form of the PRLR $\left(\mathrm{PRLR}_{\mathrm{S}}\right)$ were undetectable in all samples. The blots shown (Fig. 3A,B) are representative of three separate experiments.

Overall, the results from the Western blots and the immunocytochemistry were in close agreement. As anticipated, analysis of intact mammary glands by Western blotting shows an increase in $\mathrm{PRLR}_{\mathrm{L}}$ levels during pregnancy and lactation as compared with the gland from virgin rats. However, when the epithelial and stromal components were evaluated separately, some novel and interesting results were obtained. First, significant levels of $\operatorname{PRLR}_{\mathrm{L}}$ were present in all epithelia-free fat pads analyzed. PRLR $L_{L}$ levels of the fat pads did not appear to differ between the different physiological stages. Secondly, the stroma appeared to contain lower PRLR $\mathrm{L}_{\mathrm{L}}$ levels as compared with the epithelia, and this was seen at all physiological stages studied. Consequently, the increase in PRLR $_{L}$ levels in intact mammary glands of pregnant and lactating animals resulted from an increase in $P_{R L R}$ expression occurring within the epithelial component of the gland. Preincubation of PRLR-1 antisera with PRLR-1 peptide completely blocked specific PRLR detection in intact mammary gland samples from 18-day-pregnant and 6-day-lactating rats (data not shown).

\section{PRLR $m R N A$}

We also measured PRLR mRNA levels in intact glands, epithelia-free fat pads and isolated epithelia obtained from nonpregnant, pregnant and lactating rats by RPA that distinguished between long and short forms of the PRLR mRNA (Fig. 4A; described in Materials and Methods). Rat cyclophilin mRNA levels were used as an internal control in the assay. Figure 4B is a representative result of three separate experiments $(n=3$ for each sample). Two major bands were obtained in each sample assayed. These bands are the long form of the PRLR mRNA (252 nucleotides protected) and the cyclophilin mRNA (103 nucleotides protected). Bands corresponding to the short form PRLR mRNA (201 nucleotides protected) were undetectable in all samples. This predominance of the PRLR $_{L}$ mRNA form in all the mammary tissues agrees closely with what was seen at the protein level using Western blotting.

When the results from the RPA were quantified, it was apparent that the other analyses used to assess the PRLR levels, i.e. immunocytochemistry and Western blotting, are in close agreement with the RPA data (Fig. 4C). Specifically, $\operatorname{PRLR}_{\mathrm{L}}$ mRNA was present in both the mammary epithelia and stroma of virgin, 18-daypregnant, and 6-day-lactating rat mammary glands. The
$\mathrm{PRLR}_{\mathrm{L}}$ mRNA of the intact gland increased twofold and fourfold, respectively, during pregnancy and lactation as compared with virgin animals. In addition, a comparison of epithelia versus stroma content of the PRLR mRNA further corroborated this close correlation between all the analyses of PRLR expression used in this study, as significant levels of $P R L R_{L}$ mRNA were detected in all epithelia-free fat pads. Furthermore, the levels of stromal PRLR $_{L}$ mRNA did not differ in mammary tissues from the three physiological stages and they were always lower than those in the epithelial tissues, regardless of physiological stage. Also, epithelial $\mathrm{PRLR}_{\mathrm{L}}$ mRNA increased twofold during pregnancy and fourfold during lactation as compared with virgin rats.

\section{Discussion}

It is known that PRL affects both growth and differentiation of the mammary gland (Horseman 1999). However, it is not well understood how PRL exerts its effects in the mammary gland. For example, although the presence of the PRLR in the mammary epithelia is well established (Sakai et al. 1978, Bole-Feysot et al. 1998), there have been contradictory reports concerning the expression of PRLR in the mammary stroma (Bera et al. 1994, Reynolds et al. 1997). We report here a thorough study on the localization and quantitation of the PRLR in both the mammary stroma and the epithelia at three different developmental stages. Using immunocytochemistry, PRLR was localized in cleared fat pads and the epithelia and the stroma of intact glands. This PRLR localization was seen at all the physiological states investigated. Of particular interest was a shift that occurred in epithelial PRLR localization, from the cell membrane and perinuclear area during pregnancy to a predominantly cytosolic localization during lactation. This may imply a change in the mechanism of action of PRL as the epithelial cells progress from a state of proliferation to the stage of fully differentiated, lactating cells. Also noteworthy is the presence of PRLRs on both the apical and basal epithelial cell membranes during pregnancy. This pattern of mammary epithelial PRLR localization has been reported by others (Reynolds et al. 1997). The origin of the apical PRLR is not known. It could be from intracellular stores specifically targeted to the apical membrane, or from recycling of receptors from the basal membranes, as has been suggested by Kelly and Rozakis-Adcock (1991). In either case, the presence of PRLRs at the apical membrane suggests these receptors could be involved in autocrine/paracrine mechanisms of locally synthesized PRL (Ben-Jonathan et al. 1996).

Western blot analysis revealed the predominance of the $\mathrm{PRLR}_{\mathrm{L}}$ in all the mammary tissues, migrating as three major bands of 88,90 and $92 \mathrm{kDa}$. These results are in agreement with previous studies on the rat liver and the 
intact mammary gland (Boutin et al. 1988, Guillaumot \& Cohen 1994). In some samples of the isolated epithelial cells and of intact mammary glands, additional, lower molecular weight bands were observed. These were particularly prevalent in samples from tissues with very high levels of the PRLR. Therefore, we predict that these lower molecular weight bands resulted from a faster rate of receptor degradation under conditions of increased PRLR expression. Confirming the results from the immunocytochemistry, PRLRs were detected in both mammary epithelia and stroma, with PRLR levels higher in the epithelia at all physiological stages studied. Furthermore, epithelial $\operatorname{PRLR}_{L}$ levels increased while stromal PRLR remained constant, indicating that most if not all the increase in PRLR expression seen in the mammary gland

A

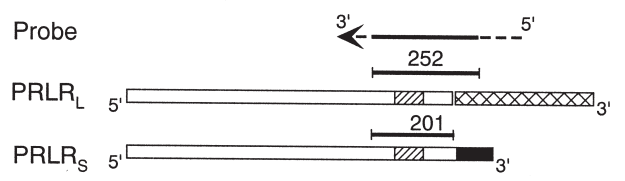

B

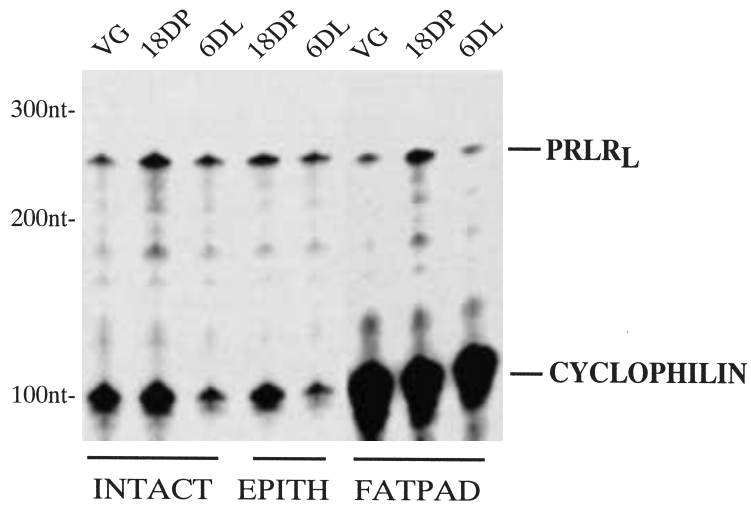

C

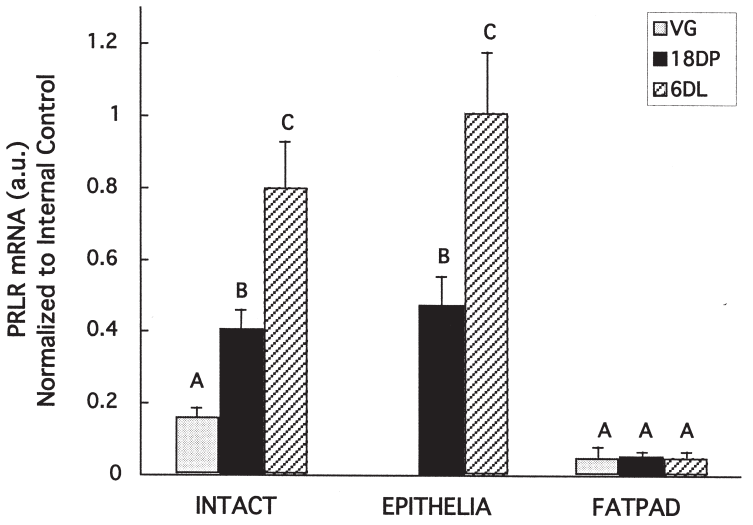

during pregnancy and lactation takes place in the epithelia. It should also be pointed out that the $\mathrm{PRLR}_{\mathrm{L}}$ was found to be present as three major isoforms, probably representing different levels of glycosylation of the receptor (Kelly \& Rozakis-Adcock 1991, Bolander 1999). The significance of these different isoforms of the $\mathrm{PRLR}_{\mathrm{L}}$ is, at present, not understood.

Assessment of the PRLR mRNA confirmed the results obtained with the PRLR protein and show that the PRLR mRNA is present in both the mammary epithelia and the stroma. As anticipated, PRLR $\mathrm{L}_{\mathrm{L}} \mathrm{mRNA}$ levels were higher in epithelia than in stroma at all stages examined. Also, epithelial PRLR $\mathrm{L}_{\mathrm{L}} \mathrm{mRNA}$ increased significantly during pregnancy and further during lactation, while stromal $\mathrm{PRLR}_{\mathrm{L}}$ mRNA levels remained constant. Taken together, our data clearly establish the presence of PRLR in both the epithelia and the stroma of the mammary gland. We also showed that most of the increase in PRLR expression seen as the mammary gland progresses from the virgin to the lactating stage is caused by the increased expression in the epithelia, not in the stroma.

The identification of hormone receptors in both mammary epithelia and stroma indicates a more complex regulatory mechanism of PRL in the mammary gland, as the hormone is probably acting on both these compartments of the mammary gland. Recent work with gene knockout mouse models has begun to elucidate the significance of receptors found in each mammary gland component. For example, Cunha and colleagues (1997)

Figure 4 Evaluation of PRLR mRNA expression in the mammary gland during three stages of development using ribonuclease protection assay. (A) Design of ribonuclease protection assay probe. Long $\left(P R L R_{L}\right)$ and short $\left(P R L R_{S}\right)$ mRNA isoforms are shown as boxes. Open boxes (the extracellular domain) and the hatched regions (the transmembrane domain) indicate sequences common to both isoforms. Crosshatched and solid areas correspond to the intracellular domain and are isoform-specific sequences. The arrow indicates the antisense RNA probe. Solid bars show position and predicted size of protected fragments for the isoforms. In the RPA, the probe protects a 252-nt fragment of the mRNA for the PRLR long form $\left(P R L R_{L}\right)$ and a 201-nt fragment of the mRNA for the PRLR short form $\left(P R L R_{\mathrm{S}}\right)$. (B) Representative phosphor-image of PRLR mRNAs of intact mammary glands (INTACT), epithelial (EPITH) and stromal (FATPAD) tissues from virgin rats (VG), 18-day-pregnant rats (18DP) and 6-day-lactating rats (6DL). Ribonuclease protection assays were carried out on $15 \mu \mathrm{g}$ total RNA per reaction for intact and epithelial samples and $30 \mu \mathrm{g}$ total RNA per reaction for stromal samples. Each lane represents an individually assayed RNA sample. (C) Quantification of PRLR mRNA in intact glands, epithelia and stromal components from virgin animals, 18-day-pregnant animals and 6-day-lactating animals. Values represent the PRLR mRNA phosphor-image counts for each group that were normalized to their respective cyclophilin mRNA phosphor-image counts. Each bar represents the mean \pm S.E.M $(n=3)$ of phosphor-imaging data in arbitrary units (a.u.). Bars with dissimilar superscripts differ significantly $(P<0 \cdot 05)$ as assessed by ANOVA followed by Fisher's protected least difference test. 
used tissue recombination techniques of normal tissues and tissues from estrogen receptor (ER) knockout mice to demonstrate that expression of the ER in the mammary stroma, not epithelia, is essential for mammary ductal elongation. Using similar methods, Brisken et al. (1998) recombined normal tissues with progesterone receptor (PR) knockout tissues to reveal that PR in the epithelia, not the stroma, is required for ductal side branching and alveolar development to occur. At the present time, the importance of stromal PRLRs is unclear. However, circumstantial evidence supports a role for stromal PRLR in regulating mammary gland development. In a recent report, mammary development was monitored after epithelia from PRLR knockout mice were transplanted into fat pads of wild-type mice. Interestingly, the ductal branching and terminal end bud progression was normal in the PRLR knockout epithelia growing in wild-type stroma whereas ductal branching and end bud progression was impaired in the PRLR knockout mice (Brisken et al. 1999). The investigators proposed that this impairment in mammary gland development in the PRLR knockout animals was caused by insufficient synthesis of progesterone as PRL is a known stimulator of progesterone synthesis (Galosy \& Talamantes 1995). However, based on the results we present here, we can now speculate that PRL is acting directly on the mammary stroma to facilitate ductal branching and end bud progression. Overall, studies using knockout animals have begun to define more precise roles for hormones and show that knockout models are a valuable resource for the study of mammary development.

It is tempting here to speculate how PRL might be acting on the stroma to regulate epithelial development. The possibilities are numerous. For example, PRL is known to regulate the expression of lipoprotein lipase (LPL) in the mammary gland and could thereby be affecting mammary gland development (Zinder et al. 1974, Hang \& Rillema 1997). The activity of LPL in the mammary gland, an enzyme important in fatty acid metabolism, rises during pregnancy and lactation (Zinder et al. 1974, Jensen et al. 1994). Studies have revealed high concentrations of LPL within mammary stromal adipocytes (Jensen et al. 1991), the presumed site of LPL synthesis. Our data support this hypothesis and provide a direct mechanistic link between PRL action in the stroma and LPL production there. PRL could also be affecting mammary gland development by directly stimulating leptin synthesis in the stroma, as leptin mRNA has been detected in mammary tissue (Aoki et al. 1999) and PRL has been shown to stimulate leptin secretion in adipose tissue in rats (Gualillo et al. 1999). Therefore, it is likely that PRL stimulates leptin production in the mammary stroma. This could be very significant for stromalepithelial cell interactions, as leptin receptors have been localized to mammary epithelia (Laud et al. 1999). As mentioned above, the ER in the mammary stroma is essential for normal mammary gland development. As
PRL is an important regulator of the ER in the mammary gland (Muldoon 1987), the stromal PRLR may be directly involved in maintaining ER synthesis in the mammary stroma, thus providing an important link between estrogen activity in the stroma and mammary gland development. Each of these studies provides strong evidence for the direct action of PRL at the mammary stroma. A recent study by Gallego et al. (2001) evaluates signal transducer and activator of transcription 5 (Stat 5) activation by PRL, $\mathrm{GH}$ and epidermal growth factor in the mammary stromal and epithelial compartments. This study uses multiple knockout models and demonstrates that PRL activates Stat 5 only in the epithelium. Therefore, PRL is probably using alternative signaling molecules in the stroma, given that PRL can activate a variety of signaling pathways (Freeman et al. 2000).

The stroma is the site of synthesis of a number of growth factors, such as hepatocyte growth factor, epidermal growth factor, keratinocyte growth factor, heregulin and insulin-like growth factors-I and -II. (Hovey et al. 1999). All these growth factors are known to regulate mammary gland development (Horseman 1999). It is not known, at present, if PRL regulates any of these growth factors directly or indirectly, but this is possible, considering the widespread effects PRL has on mammary gland growth and differentiation.

In conclusion, we have demonstrated here, for the first time, that the PRLR is expressed both in the epithelia and the stroma of the rat mammary gland. We have also shown that while the expression of PRLR in the mammary epithelia increased significantly as the mammary gland progressed from virgin to lactating stage, the PRLR in the stroma remained constant. This study provides the first evidence supporting a direct role for PRL in both the epithelia and the stroma of the mammary gland. At this time, we do not know the significance of PRLR expression in the mammary stroma. However, we have suggested several routes by which PRL may affect mammary development by acting through its stromal receptor.

\section{Acknowledgements}

We wish to thank Meghan McCarty for technical assistance with the RPAs and Huy Dao for assistance with animal surgery. We also thank Bob Kalpin and Dr Yonca Ilkbahar for helpful discussions. This work was supported by NIH Grant CA-71590.

\section{References}

Aoki N, Kawamura I M \& Matsuda T 1999 Lactation-dependent down regulation of leptin production in mouse mammary gland. Biochimica et Biophysica Acta 1427 298-306.

Ben-Jonathan N, Mershon JL, Allen DL \& Steinmetz RW 1996 Extrapituitary prolactin: distribution, regulation, functions, and clinical aspects. Endocrine Reviews 17 639-669. 
Bera TK, Hwang SI, Swanson SM, Guzman RC, Edery M \& Nandi S 1994 In situ localization of prolactin receptor message in the mammary glands of pituitary-isografted mice. Molecular and Cellular Biochemistry 132 145-149.

Bolander FF 1999 Regulation of prolactin receptor glycosylation and its role in receptor location. Molecular and Cellular Endocrinology 149 85-92.

Bole-Feysot C, Goffin V, Edery M, Binart N \& Kelly PA 1998 Prolactin (PRL) and its receptor: actions, signal transduction pathways and phenotypes observed in PRL receptor knockout mice. Endocrine Reviews 19 225-268.

Boutin J, Jolicoeur C, Okamura J, Gagnon J, Edery M, Shirota M, Banville D, Duranter-Fourt I, Dijiane J \& Kelly PA 1988 Cloning and expression of the rat prolactin receptor, a member of the growth hormone/prolactin receptor gene family. Cell 53 69-77.

Brisken C, Park S, Vass T, Lydon JP, O'Malley B \& Weinberg RA 1998 A paracrine role for the epithelial progesterone receptor in mammary gland development. PNAS 95 5067-5081.

Brisken C, Kaur S, Chavarria TE, Binart N, Sutherland RL, Weinberg RA, Kelly PA \& Ormandy CJ 1999 Prolactin controls mammary gland development via direct and indirect mechanisms. Developmental Biology 210 96-106.

Camarillo IG, Thordarson G, Ilkbahar YN \& Talamantes F 1998 Development of a homologous radioimmunoassay for mouse growth hormone receptor. Endocrinology 139 3585-3589.

Chomczynski P \& Sacchi N 1987 Single step method of RNA isolation by guanidinium thiocyanate-phenol-chloroform extraction. Analytical Biochemistry 162 156-159.

Cunha G, Young P, Horn Y, Cooke P, Taylor J \& Lubahn D 1997 Elucidation of a role for stromal steroid hormone receptors in mammary gland growth and development using tissue recombinations. Journal of Mammary Gland Biology and Neoplasia 2 393-402.

DeOme KB, Faulkin LJ, Bern HA \& Blair PB 1959 Development of mammary tumors from hyperplastic alveolar nodules transplanted into gland-free mammary fat-pads of female $\mathrm{C} 3 \mathrm{H}$ mice. Cancer Research 19 515-520.

Fendrick JL, Raafat AM \& Haslam SZ 1998 Mammary gland growth and development from the postnatal period to postmenopause: ovarian steroid receptor ontogeny and regulation in the mouse. Journal of Mammary Gland Biology and Neoplasia 3 7-22.

Forsyth IA 1989 Growth factors in mammary gland function. Journal of Reproduction and Fertility 85 759-770.

Freeman ME, Kanyicska B, Lerant A \& Nagy G 2000 Prolactin: structure, function, and regulation of secretion. Physiological Reviews 80 1523-1631.

Freemark M, Fleenor D, Driscoll P, Binart N \& Kelly P 2001 Body weight and fat deposition in prolactin receptor-deficient mice. Endocrinology 142 532-537.

Gallego MI, Binart N, Robinson GW, Okagaki R, Coschigano KT, Perry J, Kopchick JJ, Oka T, Kelly PA \& Hennighausen L 2001 Prolactin, growth hormone, and epidermal growth factor activate Stat5 in different compartments of mammary tissue and exert different and overlapping developmental effects. Developmental Biology 229 163-175.

Galosy S \& Talamantes F 1995 Luteotropic actions of placental lactogens at mid pregnancy in the mouse. Endocrinology 136 3993-4003.

Goffin V \& Kelly PA 1997 The prolactin/growth hormone receptor family: structure/function relationships. Journal of Mammary Gland Biology and Neoplasia 2 7-17.

Goffin V, Binart N, Clement-Lacroix P, Brouchard B, Bole-Feysot C, Edery M, Lucas BK, Touraine P, Pezet A, Maaskant R, Pichard C, Helloco C, Baran N, Favre H, Bernichtein S, Allamando A, Ormandy C \& Kelly PA 1999 From the molecular biology of prolactin and its receptor to the lessons learned from knockout mice models. Genetic Analysis: Biomolecular Engineering 15 189-201.
Gualillo O, Lago F, Garcia M, Menendez C, Senaris R, Casanueva FF \& Dieguez C 1999 Prolactin stimulates leptin secretion by rat white adipose tissue. Endocrinology 140 5149-5153.

Guillaumot P \& Cohen H 1994 Heterogeneity of the prolactin receptor in the rat mammary gland and liver during various physiological states. Journal of Endocrinology 141 271-278.

Hang J \& Rillema JA 1997 Prolactin's effects on lipoprotein lipase (LPL) activity and on LPL mRNA levels in cultured mouse mammary gland explants. Proceedings for the Society of Experimental Biology and Medicine 214 161-166.

Horseman ND 1999 Prolactin and mammary gland development. Journal of Mammary Gland Biology and Neoplasia 4 79-88.

Hovey RC, McFadden TB \& Akers RM 1999 Regulation of mammary gland growth and morphogenesis by the mammary fat pad: a species comparison. Journal of Mammary Gland Biology and Neoplasia 4 53-68.

Ilkbahar YN, Thordarson G, Camarillo IG \& Talamantes F 1999 Differential expression of the growth hormone receptor and growth hormone-binding protein in epithelial and stroma of the mouse mammary gland at various physiological stages. Journal of Endocrinology 161 77-87.

Jensen DR, Bessesen DH, Etienne J, Eckel RH \& Neville MC 1991 Distribution and source of lipoprotein lipase in mouse mammary gland. Journal of Lipid Research 32 733-742.

Jensen DR, Gavigan S, Sawicki V, Witsell DL, Eckel RH \& Neville MC 1994 Regulation of lipoprotein lipase activity and mRNA in the mammary gland of the lactating mouse. Biochemical Journal 298 321-327.

Kelly PA \& Rozakis-Adcock M 1991 Mutational analysis of the ligand-binding domain of the prolactin receptor. Journal of Biological Chemistry 266 16472-16477.

Kelly PA, Ali S, Rozakis M, Goujon L, Nagano M, Pellegrini I, Gould D, Djiane J, Edery M, Finidori J \& Postel-Vinay MC 1993 The growth hormone/prolactin receptor family. Recent Progress in Hormone Research 48 123-163.

Laud K, Gourdou I, Belair L, Keisler DH \& Djiane J 1999 Detection and regulation of leptin receptor mRNA in ovine mammary epithelial cells during pregnancy and lactation. FEBS Letters 463 194-198.

Lincoln DT, Sinowatz F, El-Hifnawi E, Hughes RL \& Waters M 1995 Evidence of a direct role for growth hormone (GH) in mammary gland proliferation and lactation. Anatomy, Histology and Embryology 24 107-115.

Ling C, Hellgren G, Gebre-Medhin M, Dillner K, Wennbo H, Carlsson B \& Billig H 2000 Prolactin (PRL) receptor gene expression in mouse adipose tissue: increases during lactation and in PRL-transgenic mice. Endocrinology 141 3564-3572.

Lyons WR, Li CH \& Johnson RE 1958 Hormonal control of mammary growth and lactation. Recent Progress in Hormone Research 14 219-254.

Mertani HC, Garcia-Caballero T, Lambert A, Gerard F, Palayer C, Boutin JM, Vonderhaar BK, Waters MJ, Lobie PE \& Morel G 1998 Cellular expression of growth hormone and prolactin receptors in human breast disorders. International Journal of Cancer $\mathbf{7 9}$ 202-211.

Muldoon TG 1987 Prolactin mediation of estrogen-induced changes in mammary tissue estrogen and progesterone receptors. Endocrinology 121 141-149.

Nagano M \& Kelly PA 1994 Tissue distribution and regulation of rat prolactin receptor gene expression. Journal of Biological Chemistry 269 13337-13345.

Nandi S 1958 Endocrine control of mammary gland development and function in the $\mathrm{C} 3 \mathrm{H} / \mathrm{He} \mathrm{Crg} 1$ mouse. Journal of the National Cancer Institute 21 1039-1063.

Reynolds C, Montone KT, Powell CM, Tomaszewski JE \& Clevenger CV 1997 Expression of prolactin and its receptor in human breast carcinoma. Endocrinology 138 5555-5560. 
Rillema JA 1994 Development of the mammary gland and lactation. Trends in Endocrinology and Metabolism 5 149-154.

Sakai S, Enami J, Nandi S \& Banerjee MR 1978 Prolactin receptor on dissociated mammary epithelial cells at different stages of development. Molecular and Cellular Endocrinology 12 285-298.

Shyamala G 1999 Progesterone signaling and mammary gland development. Journal of Mammary Gland Biology and Neoplasia 4 89-104.
Smith WC, Linzer DI \& Talamantes F 1988 Detection of two growth hormone receptor mRNAs and primary translation products in the mouse. PNAS 85 9576-9579.

Zinder O, Hamosh M, Fleck TRC \& Scow RO 1974 Effect of prolactin on lipoprotein lipase in mammary gland and adipose tissue of rats. American Journal of Physiology 226 744-747.

Received 29 May 2001

Accepted 13 June 2001 